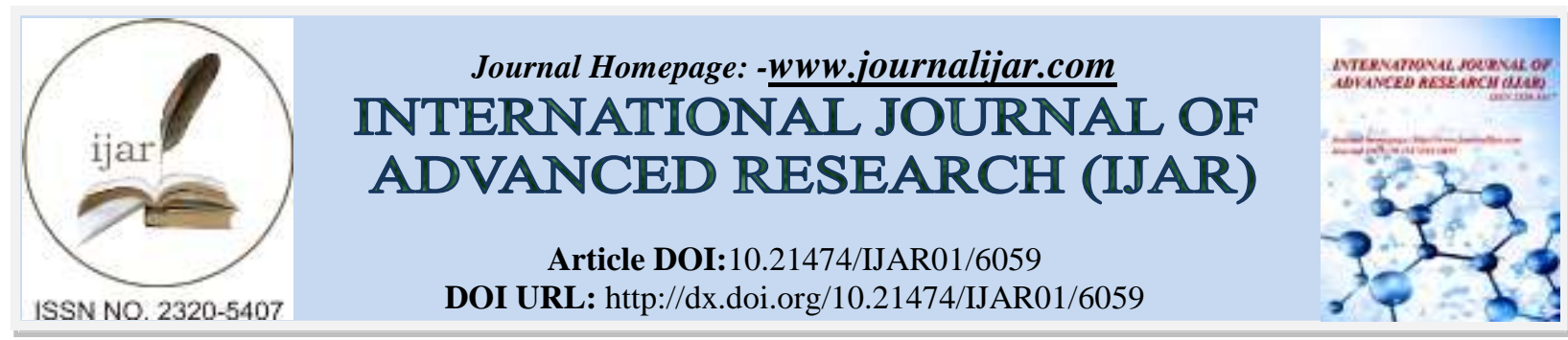

RESEARCH ARTICLE

\title{
CLASS II CORRECTION BY MOLAR DISTALIZATION WITH PENDULUM APPLIANCE- A CASE REPORT.
}

\author{
Dr. Abdul Baais Akhoon ${ }^{1}$, Prof. Dr. Mohammad Mushtaq ${ }^{2}$ and Dr. Aasiya Ishaq ${ }^{3}$. \\ 1. PG student, Department of Orthodontics and Dentofacial Orthopaedics, Govt. Dental College, Srinagar. \\ 2. Professor and Head, Department of Orthodontics, Govt. Dental College and Hospital, ShereenBagh, Srinagar, \\ University of Kashmir. \\ 3. Junior Resident, Dept. of Orthodontics, Govt. Dental College, Srinagar.
}

\section{Manuscript Info}

Manuscript History

Received: 14 October 2017

Final Accepted: 16 November 2017

Published: December 2017

Key words:-

Class II, Class I, Pendulum appliance,

Distalization, Nonextraction.

\section{Abstract}

12-year female patient presented skeletal class I jaw base with unilateral Class II molar relationship with well aligned lower arch and lower incisors upright over basal bone. Distalization was planned in upper arch to correct Class II molar relation and mild upper incisor proclination. Modified Pendulum appliance was used to distalize upper molar. Bilateral Class I molar relationship was achieved and incisor proclination reduced in a span of 18 months.

Copy Right, IJAR, 2017,. All rights reserved.

\section{Introduction:-}

Correction of Angle's Class II malocclusion with a non-extraction approach requires distal movement of the maxillary dentition or mesial movement of the mandibular dentition or combination of both. A myriad of devices have been developed over the years in this regard which have been used to distalize the maxillary molars and shown agreeable clinical outcomes. The creation and use of intra maxillary intraoral appliances for molar distalization in Class II malocclusion have been made possible through advancements in biomechanics and technology and materials that have allowed the delivery of light and constant forces over a wide range of deactivation ${ }^{1}$. With extra oral mechanisms implementing molar distalization, the success of the treatment will decisively rely on the patient's compliance ${ }^{2}$. Since the early 1980 s, therapeutic approaches and devices have been focussed increasingly on options for correcting malocclusions in which patient compliance could be almost ignored. As a main approach of noncompliance appliances, intra arch devices for molar distalization have been introduced. Clinical application of Pendulum appliance, Repelling magnets, ${ }^{3,4}$ Acrylic Cervical occipital (ACCO) ${ }^{5}$ Wilson Bimetric Distalizing Arch (BDA), ${ }^{6,7}$ Distal jet, ${ }^{8,9} \mathrm{~K}$-loop, ${ }^{10}$ and Jasper jumper ${ }^{11}$ etc. demonstrated promising results. However, almost all the appliances show adverse reciprocal effects, such as flaring of the anterior teeth, mesial movement of the mandibular teeth, and extrusion of the premolars ${ }^{12}$.

It has been widely accepted that clinical management of intra arch devices is simple and efficient. As an important part of this intra arch system, the Pendulum Appliance was first introduced by Hilgers in $1992 .{ }^{13}$ Since then, many variations have emerged and the clinical application of the pendulum appliance has demonstrated good result. The Pendulum appliance is simple, non compliant, easy to fabricate in the dental lab and easy to activate. This case report describes unilateral distalization of molar with modified Pendulum appliance in Class II subdivision malocclusion. 


\section{Patient Selection:-}

Distalization therapy is indicated in cases with Class II molar relation with Class I skeletal jaw base, brachyfacial or mesofacial pattern, horizontal growth pattern, healthy tempromandibular joint and upright lower teeth along with good alignment. It is imperative to determine the space available for maxillary first molar with respect to the Ricketts' pterygoid vertical line on the lateral cephalogram. As a rule, this distance is calculated as the patient's age plus $3 \mathrm{~mm}$ in growing individuals and a minimum of $18 \mathrm{~mm}$ in non growing individuals.

\section{Case Report:-}

12-year female presented with the chief complaint of having proclination of her upper front teeth. No relevant medical history was present. On clinical appraisal, no abnormality was detected with temporomandibular joint. Her facial form was mesoprosopic and symmetric, with a straight and harmonious soft tissue profile (Fig. 1).

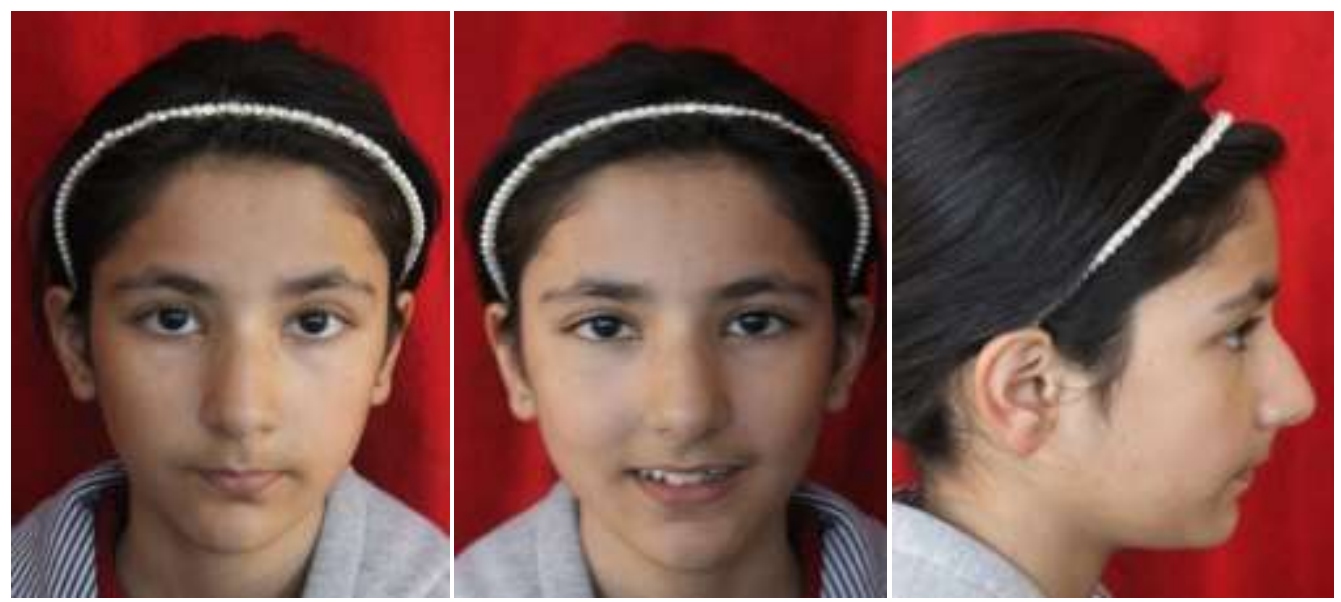

Fig. 1:-Pre treatment extra oral photographs.

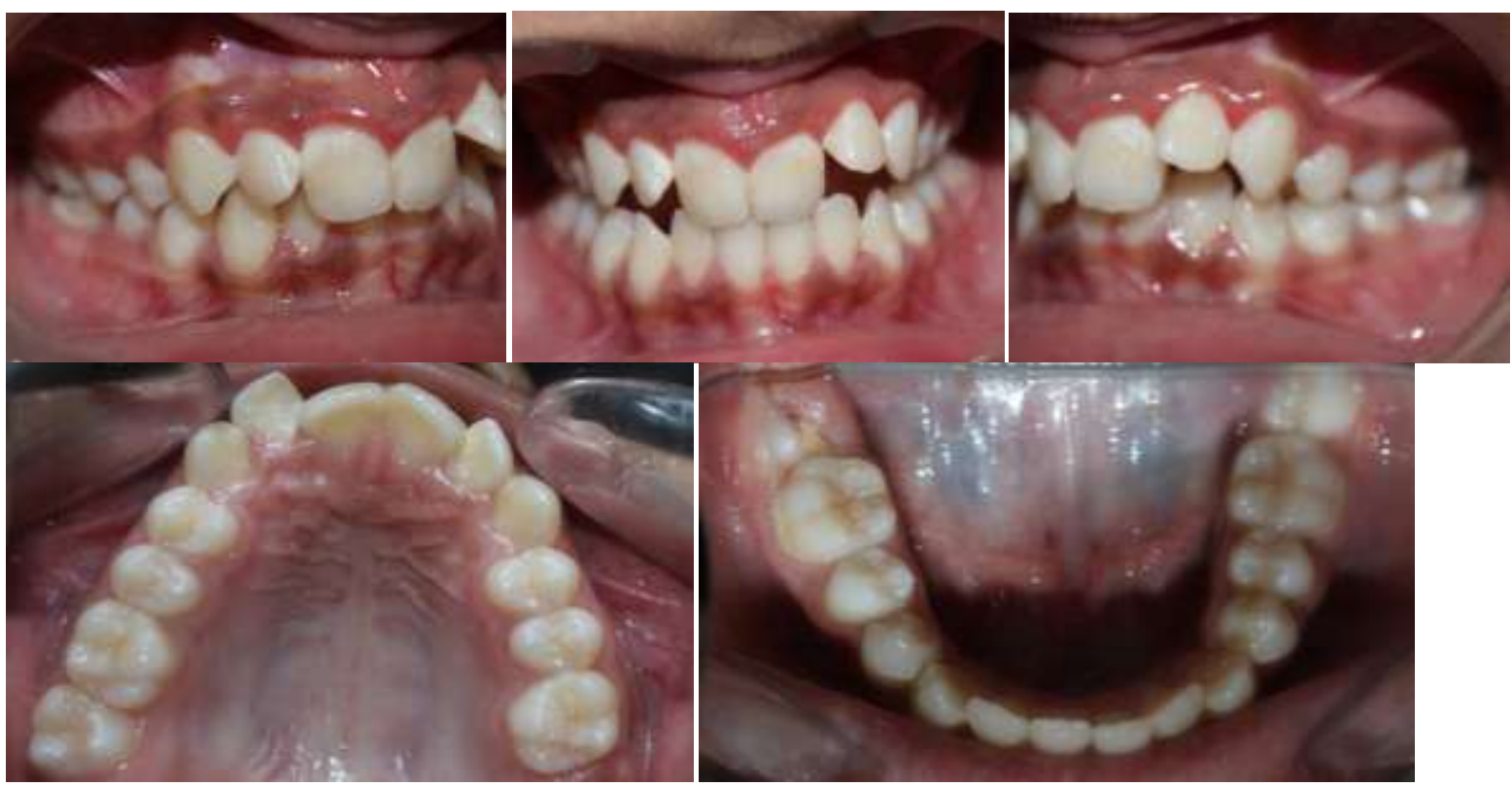

Fig. 2:-Pre treatment intra oral photographs 


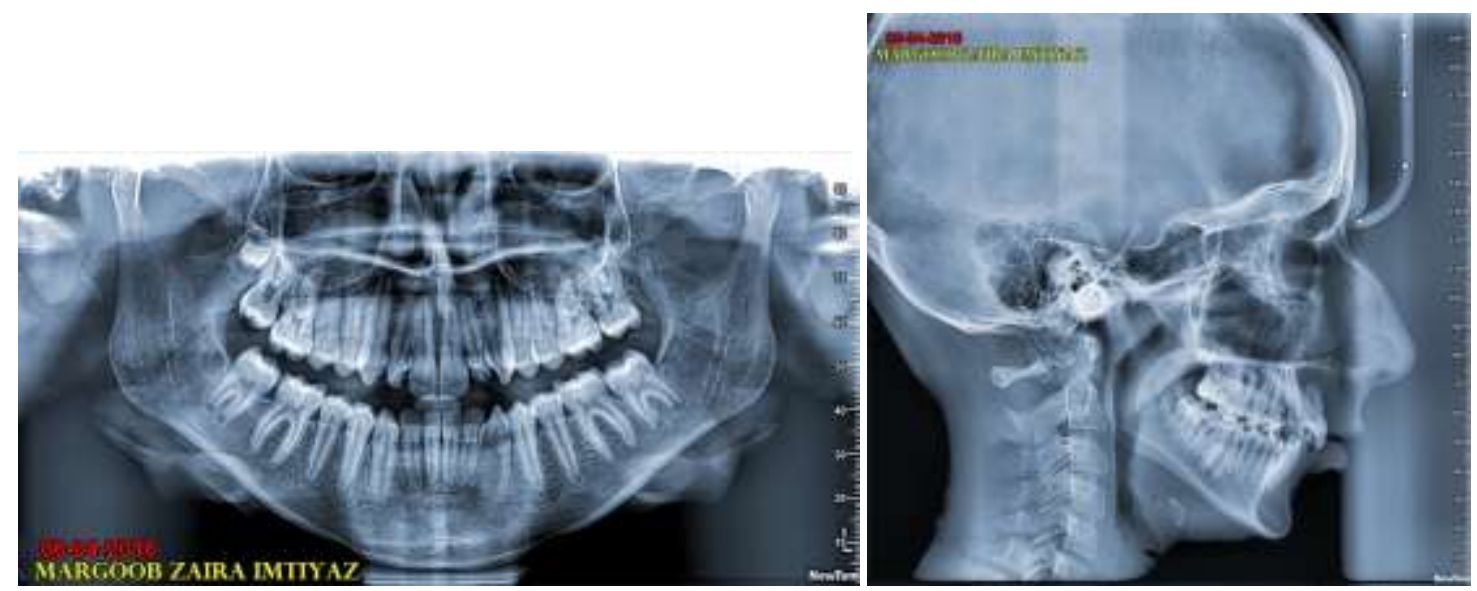

Fig. 3:-Pre treatment panoramic and lateral cephalometric radiographs

Intra orally, she had an end-on molar relation on the left side and Class I molar relation on the right side, 3 mm overjet and $20 \%$ overbite (Fig. 2). Upper midline was shifted to right side by $2 \mathrm{~mm}$ with respect to facial midline. Lateral cephalogram showed ANB of $2^{\circ}$ and Wits appraisal of $3 \mathrm{~mm}$, indicative of a Class I skeletal relation. The skeletal pattern was horizontal as evidenced by the SN-MP angle of $28^{\circ}$. Patient had proclined maxillary incisor with U1-SN $110^{\circ}$, normally inclined lower incisor with L1-MP 95(Fig. 3). The distance between Ricketts' PTV line and distal surface of maxillary first molar was $13.5 \mathrm{~mm}$.

\section{Treatment Objectives:-}

Treatment objectives were to correct end-on molar and canine relation with respect to upper left quadrant, dental midline correction with respect to facial midline and to reduce mild incisor proclination.

\section{Treatment Plan:-}

Unilateral distalization of the maxillary molars was planned using a modified Pendulum Appliance with respect to upper left quadrant, followed by fixed appliance therapy. The distance between Ricketts' PTV line and distal surface of maxillary first molar was $13.5 \mathrm{~mm}$. According to Ricketts', minimum distance required for 12 year female patient was $12 \mathrm{~mm}$. So distalization was possible.

Table 1:- Cephalometric Findings.

\begin{tabular}{|l|l|l|l|}
\hline Variable & Standard & Pre-treatment & Post-treatment \\
\hline \multicolumn{4}{|l|}{ Skeletal } \\
SNA & $82^{\circ} \pm 2^{\circ}$ & $80^{\circ}$ & $79^{\circ}$ \\
\hline SNB & $80^{\circ} \pm 2^{\circ}$ & $78^{\circ}$ & $77^{\circ}$ \\
\hline ANB & $2^{\circ}$ & $2^{\circ}$ & $2^{\circ}$ \\
\hline Go Gn - SN & $32^{\circ}$ & $32^{\circ}$ & $30^{\circ}$ \\
\hline Wits appraisal & $0 /+1 \mathrm{~mm}$ & $3 \mathrm{~mm}$ & $1 \mathrm{~mm}$ \\
\hline DENTAL & & \\
\hline
\end{tabular}

\begin{tabular}{|l|l|l|l|}
\hline $\mathbf{U 1}-\mathbf{S N}$ & $102^{\circ} \pm 2^{\circ}$ & $110^{\circ}$ & $105^{\circ}$ \\
\hline U1 - NA & $4 \mathrm{~mm} / 22^{\circ}$ & $6 \mathrm{~mm} / 25^{\circ}$ & $5 \mathrm{~mm} / 23^{\circ}$ \\
\hline L1 - NB & $4 \mathrm{~mm} / 25^{\circ}$ & $4 \mathrm{~mm} / 25^{\circ}$ & $5 \mathrm{~mm} / 28^{\circ}$ \\
\hline IMPA & $92^{\circ} \pm 5^{\circ}$ & $95^{\circ}$ & $100^{\circ}$ \\
\hline U6 - PtV & Age $+3 \mathrm{~mm}$ & $13.5 \mathrm{~mm}$ & $8.5 \mathrm{~mm}$ \\
\hline
\end{tabular}

SOFT TISSUE

\begin{tabular}{|l|l|l|l|}
\hline NASOLABIAL ANGLE & $90-110^{\circ}$ & $99^{\circ}$ & $98^{\circ}$ \\
\hline U LIP - S LINE & $0 \mathrm{~mm}$ & $1 \mathrm{~mm}$ & $1 \mathrm{~mm}$ \\
\hline L LIP - S LINE & $0 \mathrm{~mm}$ & $1 \mathrm{~mm}$ & $1 \mathrm{~mm}$ \\
\hline
\end{tabular}




\section{Treatment Progress:-}

Modified Pendulum appliance was fabricated and inserted onto the banded maxillary first molars. The appliance was activated by $90^{\circ}$, which delivered approximately 220 grams of force. The molar started moving distally. At the end of four months, the molars showed a distal movement of $5 \mathrm{~mm}$ (Fig. 4). This was followed by the use of Insta Nance Appliance as a means of retention (Fig. 5). A mid-treatment lateral cephalogram showed distalization of first molar and revealed bone deposition on the mesial aspect (Fig. 6). After the desired distalization was achieved, $0.022 \times 0.028^{\prime \prime}$ MBT brackets (Ecolite) were bonded. Alignment and levelling in the both arches was carried out by following wire sequence: (a) 0.016" heat activated nickel-titanium arch wires (b) $0.018^{\prime \prime} \mathrm{SS}$ arch wires and (c) $0.017 \times 0.025^{\prime \prime} \mathrm{SS}$ arch wires. The arch wires were cinched distal to molar to avoid maxillary and mandibular incisor proclination. Class II elastics were used on $0.017 \times 0.025^{\prime \prime}$ stainless steel wire to augment anchorage and to correct canine relation. Coordination of both the arches was carried out on $0.019 \times 0.025$ "stainless steel wire (Fig.7). Finishing was accomplished with $0.021 \times 0.025^{\prime \prime}$ titanium molybdenum alloy wire. The treatment was completed in eighteen months. At the debond visit, the patient was given a maxillary and mandibular bonded lingual retainer. The patient is being recalled every six months for follow up.
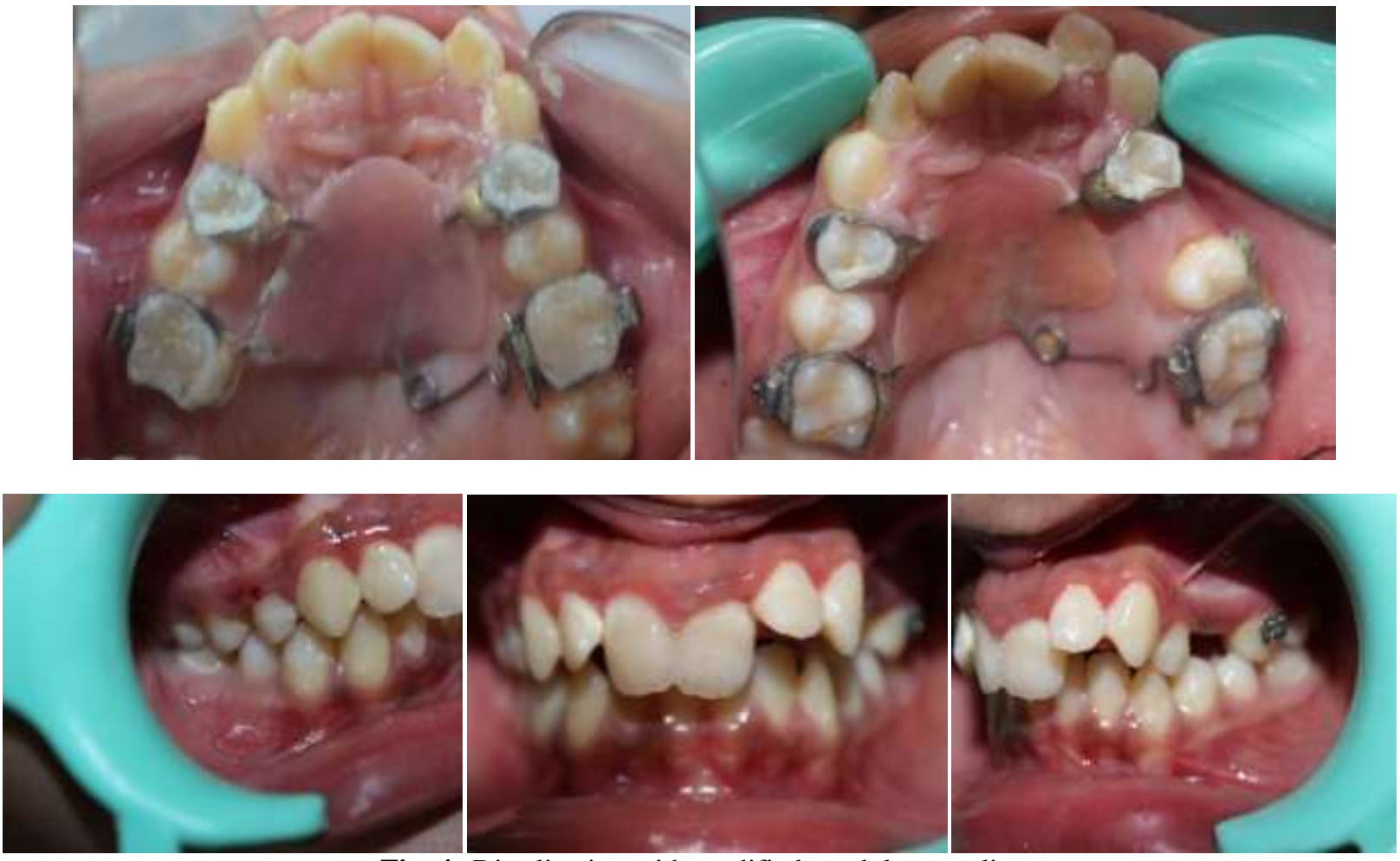

Fig. 4:-Distalization with modified pendulum appliance

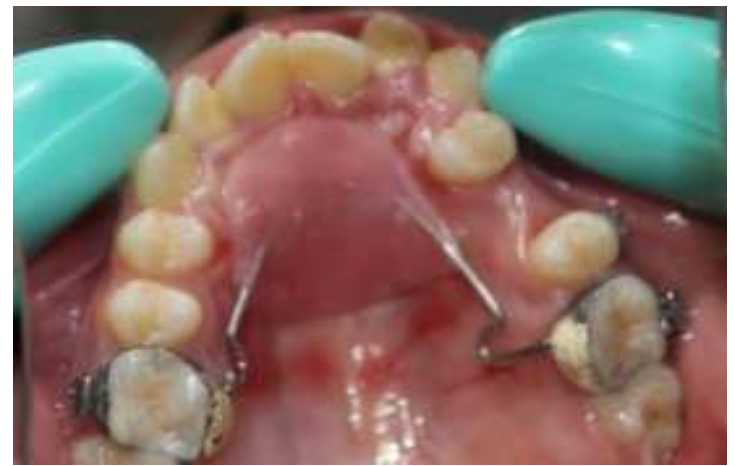

Fig. 5:-Insta-nance appliance 


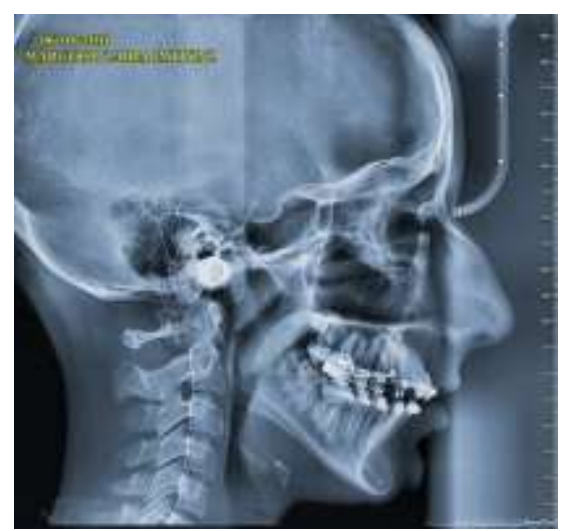

Fig. 6:-Post distalization lateral cephalogram

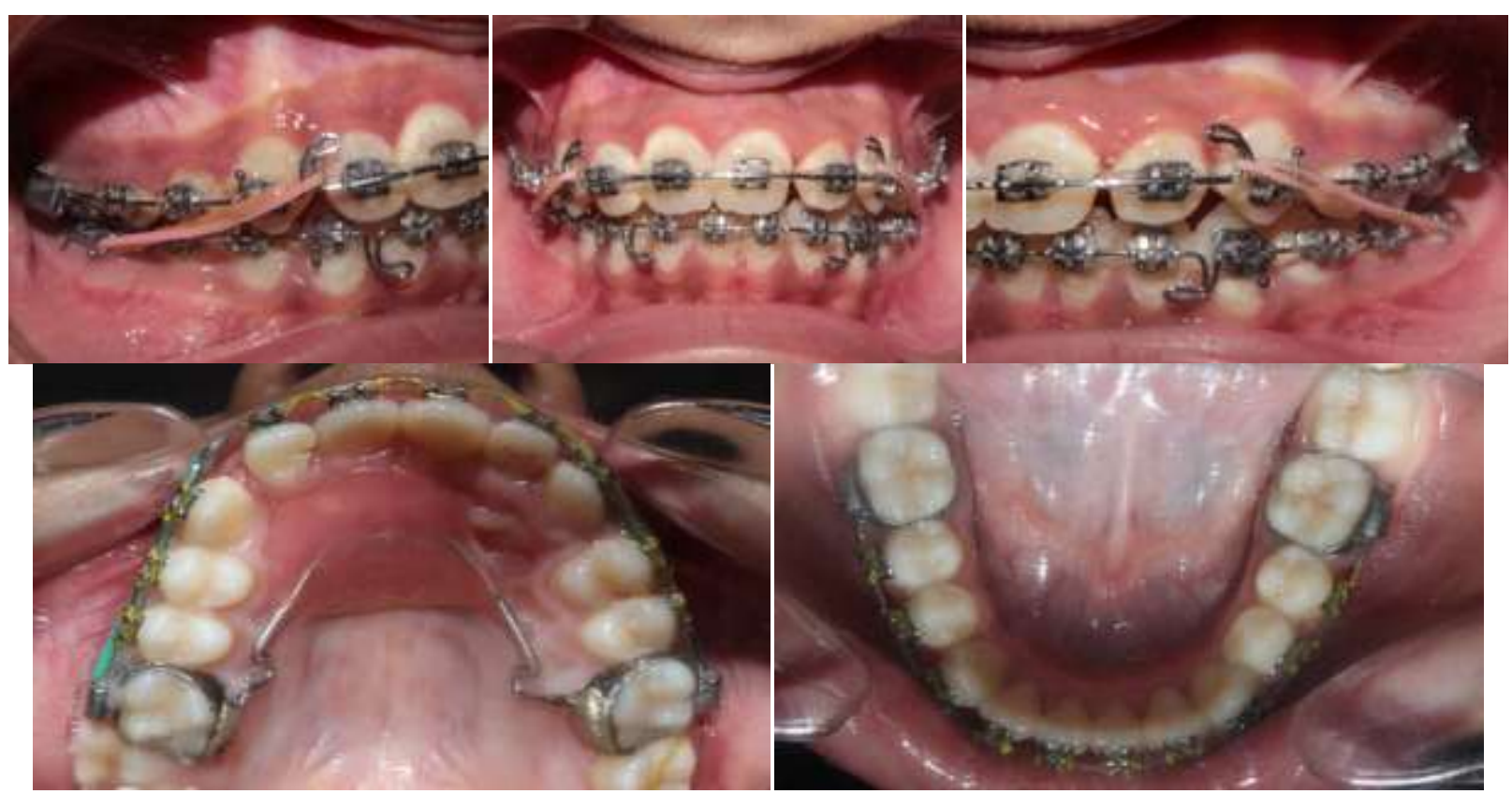

Fig. 7:-Upper and lower $19 \times 25$ stainless steel wire with class II elastics

\section{Treatment Result:-}

A good occlusion was established resulting in bilateral Class I molar and canine relation along with normal overjet and overbite (Fig. 8 and 9). The maxillary first molar was distalized by $5 \mathrm{~mm}$ in 4 months. The upper dental midline was corrected in relation to facial midline. The position and inclination of the upper incisors were normalized. The nasolabial angle presented within the normal range and upper and lower lips exhibited a normal position in relation to the E-line (Fig.10). 


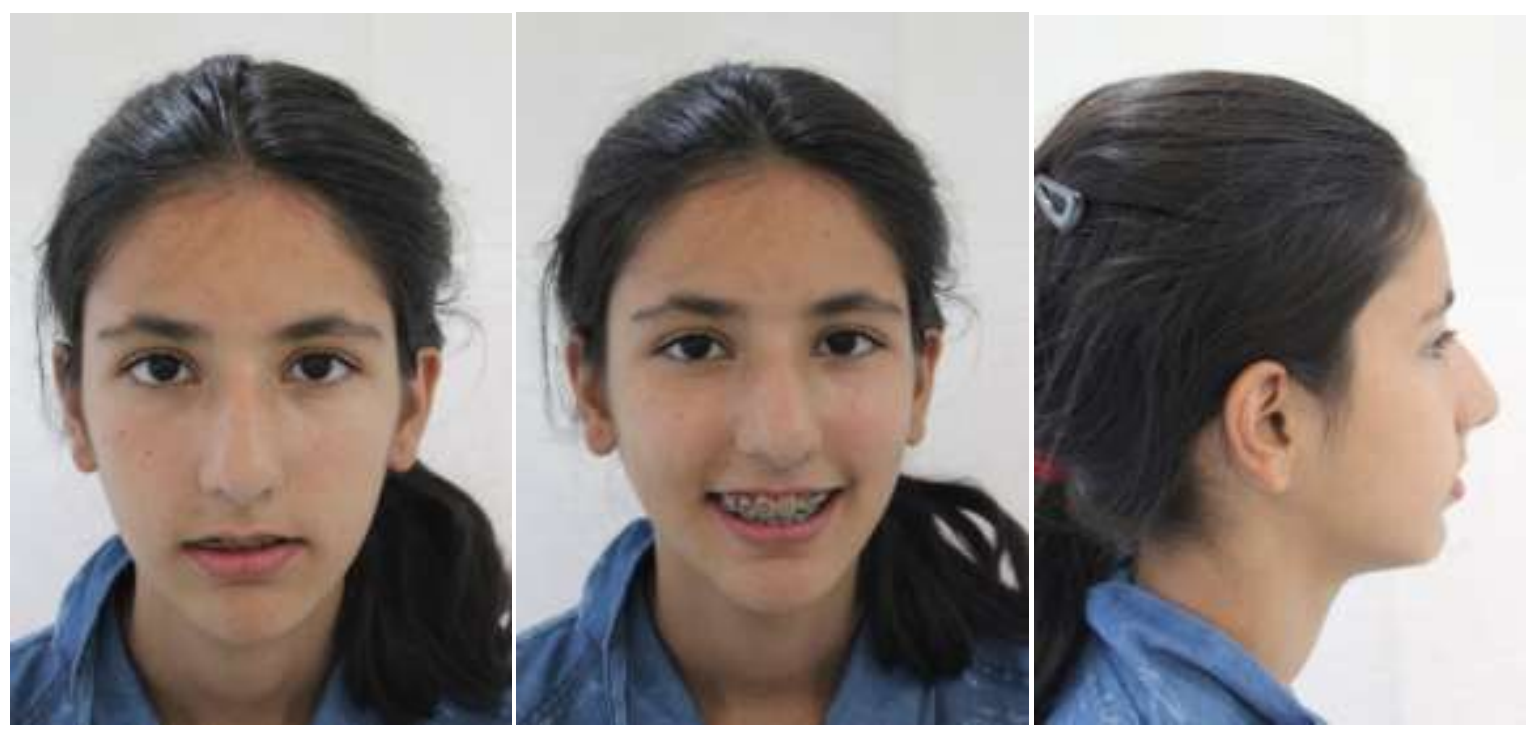

Fig. 8:-Post treatment facial photographs

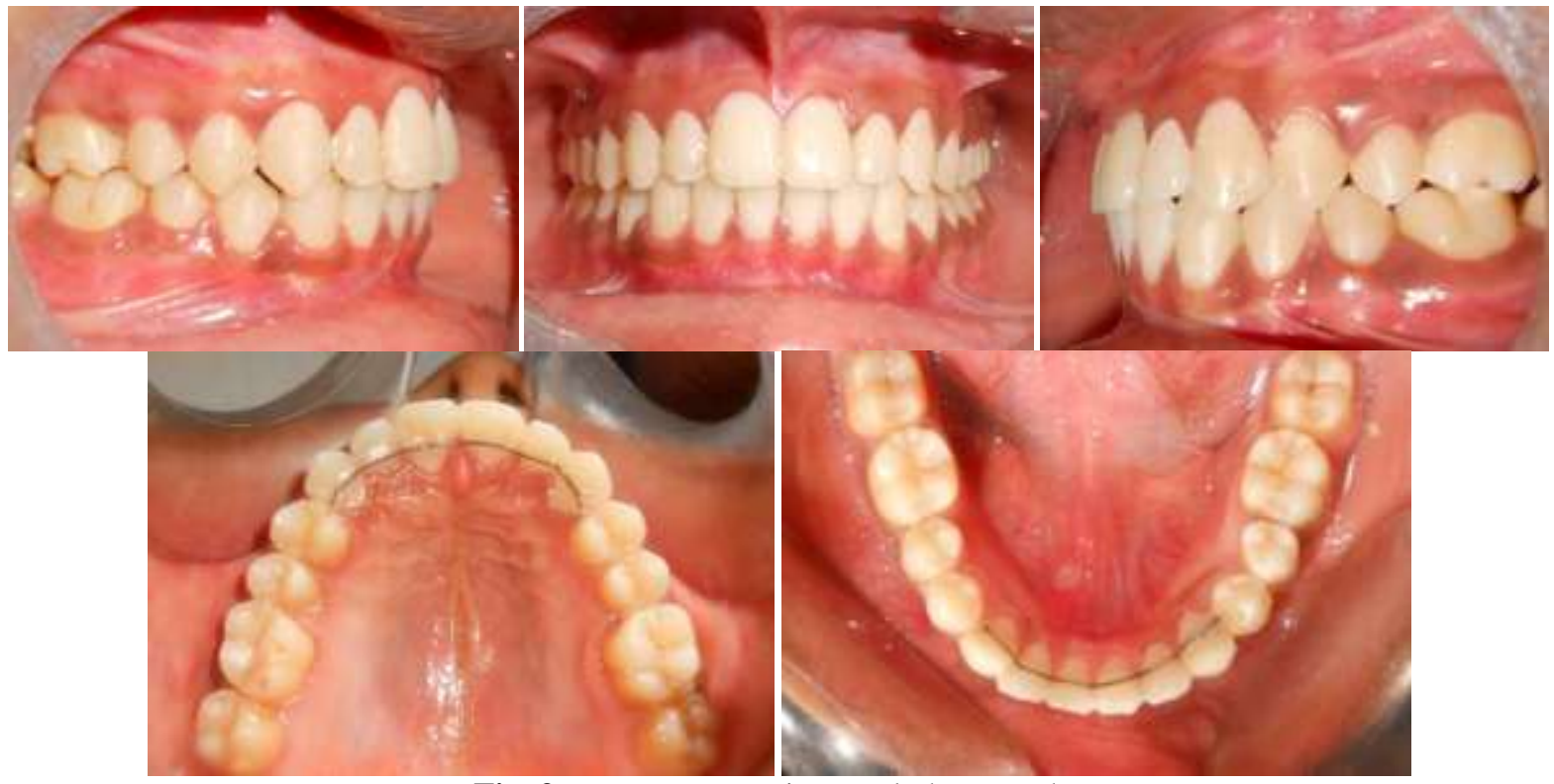

Fig. 9:-Post treatment intraoral photographs 


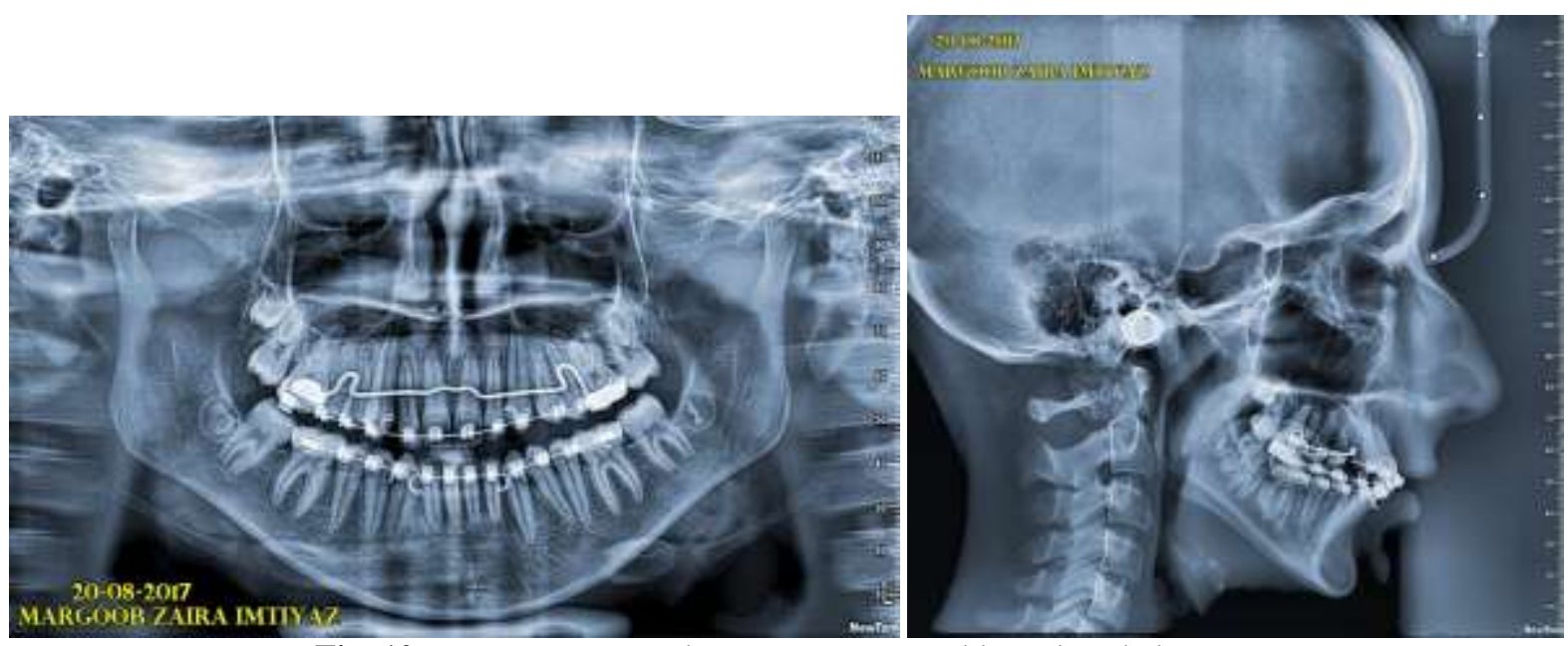

Fig. 10:-Post treatment orthopantomogram and lateral cephalogram

\section{Discussion:-}

Modified Pendulum appliance consists of a Nance button that incorporates four occlusal rests that are bonded either to the deciduous molars or to the first and second bicuspids. An alternative method is to solder retaining wires to bands on the maxillary first bicuspids. Two 0.032 " TMA springs inserted into 0.036 " lingual sheath on the maxillary molar bands are used as active elements for molar distalization. The springs are mounted as close to the centre and distal edge of the acrylic button as possible to produce a broad, swinging arc (or pendulum) of force. Each spring consists of a closed helix, an omega-shaped adjustable horizontal loop for molar expansion and prevention of the cross-bite following the palatal movement of the molar ${ }^{14}$. Force is applied occlusally with respect to the centre of resistance of the molar. Therefore, the molars are not distalized in a bodily fashion, but distal tipping followed by uprighting is expected.

Modified Pendulum appliance was successfully used for the unilateral distalization of maxillary first molar into a Class I molar relationship in this case. The patient's second molar had also erupted. Influence of second molar on the distal movement of the first molar remains a matter of debate. Some authors reported that the presence of second molar increases the treatment duration, ${ }^{15}$ produces more tipping of molar, ${ }^{16}$ and more anterior anchorage loss. ${ }^{17}$ On the contrary, some authors have reported that the presence and the position of second molar does not affect the amount and the type of maxillary first molar distal movement. ${ }^{18-20}$ Previous studies have indicated that the pendulum appliance produces a molar distalization between 3.14 and $6.1 \mathrm{~mm} .^{21,22} \mathrm{In}$ our case, $5 \mathrm{~mm}$ of distalization of first molar was achieved in a duration of 4 months. After the first phase of distalization treatment with Pendulum appliance, the Insta-Nance appliance was placed to stabilize the molar until the retraction of the canine was accomplished. This had the purpose of encouraging the spontaneous distal drift of the first and second premolars owing to the action of trans-septal fibers. Upper anterior teeth were retracted in the space created by distalization. There was anchorage loss of anterior teeth which was corrected during fixed appliance phase. ${ }^{23-27}$

Unilateral distalization has the advantage of stronger anchorage because the whole contralateral side is incorporated in the anchorage unit. Unilateral distalization seems to be associated with less anchorage loss and less tipping of the molar than bilateral distalization. ${ }^{28}$ Caprioglio et al revealed that subjects using Pendulum appliance showed lesser anchorage loss for a greater amount of distal molar movement. ${ }^{29}$ Superimposition showed U1 to SN was reduced from $110^{\circ}$ to $105^{\circ}$, it indicated that the upper incisors were retracted. L1 to MP was increased from $95^{\circ}$ to $100^{\circ}$ which revealed that the lower incisors were slightly proclined during treatment. These changes were not significant and did not affect post treatment stability.

\section{Conclusion:-}

Modified Pendulum appliance was found to be efficient, non-invasive and non compliant appliance for attainment of molar distalization. $5 \mathrm{~mm}$ of distalization was achieved in 4 months and Class I molar and canine relation was achieved. 


\section{Acknowledgement:-}

The author wishes to acknowledge Professor Dr. Mohammad Mushtaq, Head of the Dept. of Orthodontics, Govt. Dental College, Srinagar, for his guidance.

\section{References:-}

1. Sfondrini MF, Cacciafesta V, Sfondrini G. Upper molar distalization: a critical analysis. OrthodCraniofac Res. 2002; 5: 114-126.

2. Melsen B. Effects of cervical anchorage during and after treatment: an implant study. Am J Orthod. 1978; 73:526-540.

3. Gianelly AA, Vaitas AS, Thomas WM. The use of magnets to move molars distally. Am J OrthodDentofacialOrthop 1989; 96:161-167.

4. Bondemark L, Kurol J. Distalization of maxillary first and second molars simultaneously with repelling magnets. Eur J Orthod 1992; 14:264-272.

5. Dietz SV, Gianelly AA. Molar distalization with the acrylic cervical occipital appliance. SeminOrthod 2000; 6:91-7.

6. Wilson WL. Modular orthodontic systems. Part 1. J ClinOrthod 1978; 12:259-78.

7. Wilson WL. Modular orthodontic systems. Part 2. J ClinOrthod 1978; 12:358-75.

8. Carano A, Testa M. The distal jet for upper molar distalization. J ClinOrthod 1996; 30:374-380.

9. Carano A, Testa M. Clinical application of distal jet. RS Editore.

10. Kalra V. The K-loop molar distalizing appliance. J ClinOrthod 1995; 29(5):298-301.

11. Covell DA, Trammell DW, Boero RP, West R. A cephalometric study of Class II division 1 malocclusions treated with the Jasper Jumper appliance. Angle Orthod 1999; 69:311-20.

12. Cope JB, Buschang PH, Cope DD, Parker J, Blackwood HO III. Quantitative evaluation of craniofacial changes with Jasper jumper therapy. Angle Orthod. 1994; 64:113-122.

13. Hilgers JJ. The Pendulum appliance for class II non-compliance therapy. J ClinOrthod 1992; 26:706-14.

14. Haydar S, Uner O. Comparison of Jones jig molar distalization appliance with extraoral traction. Am J OrthodDentofacialOrthop. 2000; 117:49-53.

15. Gianelly AA, Bednar J, Dietz VS. Japanese NiTi coils used to move molars distally. Am J OrthodDentofacialOrthop. 1991; 99:564-566.

16. Bondemark L, Kurol J, Bemhold M. Repelling magnets versus superelastic nickel-titanium coils in simultaneous distal movement of maxillary first and second molars. Angle Orthod. 1994; 64:189-198.

17. Kinzinger G, Fritz U, Diedrich P. Bipendulum and quad pendulum for non-compliance molar distalization in adult patients. J OrofacOrthop. 2002; 63:154-162.

18. Bussick TJ, McNamara JA Jr. Dentoalveolar and skeletal changes associated with the pendulum appliance. Am J OrthodDentofacialOrthop. 2000; 117:333-343.

19. Byloff FK, Darendeliler MA. Distal molar movement using the pendulum appliance. Part 1: clinical and radiological evaluation. Angle Orthod. 1997; 67:249-260.

20. Muse DS, Fillman MJ, Emmerson WJ, et al. Molar and incisor changes with Wilson rapid molar distalization. Am J OrthodDentofacialOrthop. 1993; 104:556-565.

21. Chaques-Asensi J, Kalra V. Effect of the pendulum appliance on the dentofacial complex. J Clin Orthod.2001; 35:254-700

22. Fontana M, Cozzani M, Caprioglio A. Non-compliance maxillary molar distalizing appliances: an overview of the last decade. ProgrOrthod. 2012; 13:173-84.

23. Brickman CD, Sinha PK, Nanda RS. Evaluation of the Jones jig appliance for distal molar movement. Am J OrthodDentofacialOrthop. 2000; 118:49-53.

24. Mavropoulos A, Karamouzos A, Kiliaridis S, Papadopoulos MA. Efficiency of noncompliance simultaneous first and second upper molar distalization: a three-dimensional tooth movement analysis. Angle Orthod. 2005; 75:468-475.

25. Runge ME, Martin JT, Bukai F. Analysis of rapid maxillary molar distal movement without patient cooperation. Am J OrthodDentofacialOrthop. 1999; 15:153-157.

26. Gulati S, Kharbanda OP, Parkash H. Dental and skeletal changes after intraoral molar distalization with sectional jig assembly. Am J OrthodDentofacialOrthop. 1998; 14:319- 327.

27. Keles A. Maxillary unilateral molar distalization with sliding mechanics: a preliminary investigation. Eur $\mathbf{J}$ Orthod. 2001; 23:507-515. 
28. AnestisMavropoulosa; KorkmazSayinsub; FerdiAllafc; Stavros Kiliaridisd; Moschos A. Papadopoulose; AhmetOzlemKelesf. Noncompliance Unilateral Maxillary Molar Distalization: A Three-Dimensional Tooth Movement Analysis. Angle Orthod 2006; 76:382-387. 3

29. Caprioglio a, Beretta M, Lanteri C. Maxillary molar distalization: Pendulum and fast-back, comparison between two approaches for Class II malocclusion. ProgOrthod 2011; 12:8-16. 